\title{
Adherence of Older People with Diabetes to Self-Care Activities: a Study on Gender Differences

Lidiany Galdino Felix ${ }^{1}$, Alyne Fernandes Bezerra ${ }^{2}$, Luana Gislene Herculano Lemos ${ }^{3}$, Rosângela Vidal de Negreiros ${ }^{4}$, Fabíola de Araújo Leite Medeiros, Ana Paula Marques Andrade de Souza, Alana Tamar Oliveira de Sousa ${ }^{7}$, Emanuelle Malzac Freire de Santana ${ }^{2}$, Karen Krystine Gonçalves de Brito ${ }^{6}$, Suellen Duarte de Oliveira Matos ${ }^{6}$, Smalyanna Sgren da Costa Andrade ${ }^{6}$, Mirian Alves da Silva ${ }^{8}$, Elizabeth Souza Silva de Aguiar ${ }^{6}$, Iraktania Vitorino Diniz ${ }^{6}$, Mona Lisa Cavalcante Cartaxo do Nascimento9, Bernadete de Lourdes André Gouveia ${ }^{6}$, Maria Júlia Guimarães Oliveira Soares ${ }^{10}$

\section{Abstract}

Introduction: Diabetes mellitus is one of the main diseases affecting the elderly population, and the evaluation of adherence to the elderly self-care practices in diabetes is essential to reduce the occurrence of events considered preventable. The aim of this study was to evaluate the self-care activities for elderly people with diabetes mellitus and check the gender differences in adherence to these activities.

Methods: Descriptive study conducted with 50 elderlies of both genders, assisted by a Family Health Unit in a city of Paraíba within November 2013 to January 2014. The data collection used the Diabetes Questionnaire of Self-Care Activities, adapted and validated for the Brazilian context from the Summary of Diabetes Self-Care Activities Questionnaire.

Results: The elderly population studied showed satisfactory adherence to self-care activities proposed by the instrument. There were no statistically significant differences between men and women in mean adherence to the activities of self-care with diabetes. Older women had higher scores for the dimensions "general and specific food" and
1 Nurse. Doctoral Degree student of the Nursing Post-Graduation Program of Federal University of Paraíba, João Pessoa, *. Professor at Federal University of Campina Grande.

2 Master's Degree student of the Nursing Post-Graduation Program of Federal University of Paraíba. João Pessoa, Paraíba, Brazil.

3 Nurse. Substitute Professor at Federal University of Campina Grande. Campina Grande, *.

4 Nurse. Master in Nursing. Professor at Federal University of Campina Grande. Campina Grande, *

5 Nurse. Ph.D. in Nursing. Professor of the State University of Paraíba. Campina Grande, *

6 Nurse. Doctoral Degree student of the Nursing Post-Graduation Program of Federal University of Paraíba, João Pessoa, *

7 Nurse. Ph.D. in Nursing. Professor at Federal University of Campina Grande, Cuité, *.

8 Ph.D. in Nursing. Professor at Federal University of João Pessoa, *.

9 Nurse. Professor at College of Santa Emilia Rodat. João Pessoa, *

10 Titular Ph.D. Professor of the Nursing Post-Graduation Program of Federal University of Paraíba. João Pessoa, *

\section{Contact information:}

Lidiany Galdino Felix.

Address: João Francisco da Mota, 450, Catolé. Campina Grande, Paraíba, Brazil. Tel: +55 83996067461 .

झ lidiany_felix@hotmail.com 
"medication" and a lower score for the dimension "monitoring of blood glucose." Men showed a greater adherence to the dimension "foot care" and lower adherence to the item "sweet ingested."

Conclusion: The evaluated elderly have desirable self-care on the appropriate and important activities for the control of diabetes.

\section{Keywords}

Diabetes Mellitus; Self-Care; Elderly; Nursing Care.

\section{Introduction}

Diabetes Mellitus (DM) is a heterogeneous group of metabolic disorders characterized by hyperglycemia and changes in the metabolism of carbohydrates, proteins, and fats, resulting from secretion defects and/or action of insulin [1].

On the world scenario, the DM has emerged as a major public health problem that affects 415 million people, accounting for $12 \%$ of health expenditures in the world. For 2040, it is estimated that the number of people with the disease reaches more than 642 million, with a worldwide prevalence rate of $10.1 \%$ [2].

Brazil currently has the fourth place in the world ranking of countries with the highest number of cases of the disease, which affects 14.3 million people, that is $9.4 \%$ of the population. Recent estimates show that for 2040, the country will have 23.2 million people with diabetes [3].

DM is one of the main diseases affecting the elderly population [4]. The prevalence of self-reported diabetes among the elderly in Brazil increased from $17.6 \%$ in 2003 to $22.1 \%$ in 2014 [5]. The causes for the increased prevalence of diabetes during the study period cover different aspects and may be related to the greater number of diagnoses of the disease since the introduction of HiperDia program by the Ministry of Health between 2001-2003, and the growth of obesity in the elderly population [4].

Given the complexity of diabetes as a chronic disease and the increasing prevalence of older people with diabetes in contemporary society, it is seen the need to develop specific policies and interventions to promote healthy habits, prevention of acute and chronic complications to this part of the population [4]. These complications can compromise the independence, functional capacity and quality of life of the elderly [6], reducing the chances of a successful aging.

Considering that $99 \%$ of the daily care required for the treatment of diabetes is performed by the person with the disease and his families [1], the assessment of adherence of the elderly to self-care practices in diabetes is important to minimize the occurrence of events considered preventable, in addition to the costs of hospital and disease-related complications [7].

Currently, there are several tools which can be used to assess different aspects of self-care of people with diabetes as the Summary of Diabetes Self-care Activities, the Scale for Diabetic Ability Identification for Self-care, Diabetes Self-Management Questionnaire, and Diabetes Self-Care Practices questionnaire.

Among the specific instruments for assessment of self-care of people with DM, there are the Diabetes Questionnaire of Self-Care Activities (translated version) [8], which is a self-administered instrument that was translated, adapted and validated for the Brazilian context [9] from the instrument Summary of Diabetes Self-Care Activities Questionnaire [10].

Diabetes Questionnaire of Self-Care Activities proved to be a reliable and valid instrument to assess the adherence of the person with diabetes to six 
dimensions that represent distinct activities of treating the disease: food (general and specific), physical activity, medication use, monitoring of blood glucose, foot care and smoking [9, 11-14].

Considering that the studies on the evaluation of self-care among the elderly with diabetes are still incipient in the Brazilian reality, the question is: what is the adherence of older people with diabetes to self-care activities for the disease? Moreover, what are the gender differences in adherence to these activities?

In this perspective, this study aims to evaluate the self-care activities for elderly people with diabetes mellitus and check the gender differences in adherence to these activities. Such knowledge will enable the identification of the weaknesses of self-care practices among the elderly, providing necessary support for the care planning and specific interventions for diabetes education and self-care stimulus in this population group.

\section{Methods}

Descriptive study, with a quantitative approach, performed in a Family Health Unit (FHU) in the city of Campina Grande, Paraíba, Brazil. The convenience sample consisted of 50 elderlies, with a clinical diagnosis of diabetes who attended the follow-up visits of Hiperdia program between November 2013 to January 2014.

The inclusion criteria of the study participants were age less than sixty (60) years old, be registered in the selected FHU, have the diagnosis of DM, had at the time of the interview, the cognitive ability preserved to understand and respond to questions, evaluated by applying the Mini-Mental State Examination (MMSE).

Older people presenting alterations of disabling neurological order to understand the objectives of the study, the questions of applied instruments and those who refused to participate in the survey were excluded from the study.
The approach to the elderlies was conducted verbally in the waiting room of the FHU, while they waited for medical or nursing care. At that time, the elderly people were informed about the objectives and nature of the study. There was the reading aloud of the Consent and Informed Form to facilitate understanding, being asked to sign it at the end of reading.

Data collection was conducted through interviews in a private room by individual application of the Mini-Mental State Examination proving the cognitive capacity of the elderlies to participate in the study. For the elderly people with cognitive ability, other two instruments were applied: the first containing information on socioeconomic data (gender, marital status, education, family income, type of housing, housing conditions), anthropometric data (weight, height, Body Mass Index body) and health conditions (pathological personal history and current conditions); the second instrument was the Diabetes Questionnaire of Self-care Activities (QAD).

The Diabetes Questionnaire of Self-care Activities instrument is a self-administrable tool specific for evaluation of self-care activities with diabetes [9]. This assessment is standardized in a parameterized scale on weekdays ranging from 0 to 7 , with the scores indicating the frequency that people with diabetes perform their self-care activities, in the seven days before the questionnaire. The scale value is analyzed as follows: for the general food, specific food related to the intake of fruits and/or vegetables, physical activity, monitoring blood sugar, foot care, and medication, the value 0 (zero) corresponds to less desirable situation and seven (7) most favorable. For specific items related to food intake of high-fat foods and sweets, the values are inverted, and 0 (zero) is the most favorable and seven (7) the least desirable. For the evaluation of smoking habits, it is considered the proportion of smokers, the mean of cigarettes smoked and the last time that the patient has smoked [9]. 
For this study, it was considered the general adherence to self-care desirable when the average number of days of the week that the activity was performed was more than five (05) [15-16], except for the items QAD whose values are reversed [11].

For data analysis, the Statistical Package for the Social Sciences program, version 21.0 was used applying descriptive and inferential statistics. Continuous variables were presented as average and Standard Deviation (SD) followed by the minimum and maximum values. Categorical variables were described as frequencies and percentages. It was adopted $p<0.05$ as the level of statistical significance for all comparisons.

The study was approved by the Research Ethics and Research of the Committee of the Federal University of Campina Grande, CAAE: 15739113.0000.5182.

\section{Results}

The study had 50 elderlies participating, the median age of 73.64 years old ( \pm 7.13), ranging between 60 and 91 years old. As for sociodemographic cha- racteristics, the sample consisted mostly of elderly female $78 \%(n=38)$, retired $64 \%(n=32)$, with low education ( $<9$ years of study) $94 \%(n=47)$, and $48 \%$ $(n=21)$ with no education.

Regarding the comorbidities associated with diabetes, Hypertension was present in most of the elderly with $90 \%$ ( $n=45)$, followed by musculoskeletal diseases and varicose veins, both with 38\% $(n=19)$. It was also observed that $44 \%(n=20)$ of the elderly considered themselves sedentary and $56 \%(n=28)$ were overweight. The median total body mass index was $28.5 \mathrm{~kg} / \mathrm{m}^{2}$ (minimum 21.6 and maximum 41.0), and lower for men $\left(26.2 \mathrm{~kg} / \mathrm{m}^{2}\right)$.

Questions were asked based on self-care activities for the elderly in the seven days before the questionnaire to assess adherence to self-care activities between men and women, presented in Table 1, The adherence to self-care was considered satisfactory when the scores were greater or equal to five, except for the items 'eat red meat and/or derived from whole milk and eat sweets," because by being inappropriate behavior, it was expected to find lower values, exactly the opposite.

Table 1. Distribution of the domains and facets of QoL. João Pessoa, PB, 2015.

\begin{tabular}{|c|c|c|c|c|c|c|c|}
\hline \multirow{3}{*}{ Self-Care Activity } & \multicolumn{4}{|c|}{ Gender } & \multirow{3}{*}{$p$-value } & \multirow{2}{*}{\multicolumn{2}{|c|}{ Total }} \\
\hline & \multicolumn{2}{|c|}{ Female } & \multicolumn{2}{|c|}{ Male } & & & \\
\hline & $\begin{array}{c}\text { Average } \\
\text { (days) }\end{array}$ & SD & $\begin{array}{l}\text { Average } \\
\text { (days) }\end{array}$ & SD & & $\begin{array}{l}\text { Average } \\
\text { (days) }\end{array}$ & SD \\
\hline \multicolumn{8}{|l|}{ General food } \\
\hline Followed healthy diet & 5.15 & 2.72 & 3.64 & 3.52 & .134 & 4.82 & 2.95 \\
\hline Followed recommended healthy diet & 5.05 & 2.74 & 3.64 & 3.52 & .163 & 4.74 & 2.95 \\
\hline \multicolumn{8}{|l|}{ Specific food } \\
\hline Had five or more servings of fruits/vegetables & 6.31 & 1.77 & 5.18 & 3.12 & .128 & 6.06 & 2.16 \\
\hline Had foods high in fat & 3.79 & 2.91 & 3.91 & 3.04 & .910 & 3.82 & 2.91 \\
\hline Sweets intake & 1.36 & 2.30 & 0.73 & 1.19 & .386 & 1.22 & 2.11 \\
\hline \multicolumn{8}{|l|}{ Physical Activity } \\
\hline Performed physical activity for at least 30 minutes & 164 & 2.31 & 1.36 & 2.50 & .731 & 1.58 & 2.33 \\
\hline Performed specific physical activity & 1.49 & 2.24 & 1.55 & 2.46 & .941 & 1.50 & 2.27 \\
\hline \multicolumn{8}{|l|}{ Blood glucose monitoring } \\
\hline Evaluated blood sugar & 0.79 & 1.93 & 1.45 & 2.80 & .372 & 0.94 & 2.14 \\
\hline Evaluated the number of blood sugar recommended & 1.13 & 2.36 & 1.27 & 2.83 & .865 & 1.16 & 2.44 \\
\hline
\end{tabular}




\section{Self-Care Activity}

\section{Foot care}

Examined the feet

Examined the inside of shoes before put them

Dried between the toes after washing them

Medication

Took medications as recommended

Took insulin injections as recommended

Took the recommended diabetes pills

SD: Standard Deviation for the activities of self-care, in

The results presented in Table 1 indicates that there were no statistically significant differences between men and women in mean adherence to the activities of self-care to diabetes.

The general analysis of the average adherence of women to items of the Diabetes Questionnaire of Self-care Activities showed a higher score for the items "Had five or more servings of fruits/vegetables" (6.31 \pm 1.77 days) and "took the recommended diabetes pills" (6.28 \pm 2.15 days) and a lower score for the item "Evaluated blood sugar" (0.79 \pm 1.93). Men showed a greater adherence to the item "Examined the inside of shoes before put them" (6.36 \pm 2.11 days) and lower adherence to the item "sweet intake" (0.73 \pm 1.19 days ) considered appropriate activities and very important for the control of diabetes.

As for items Diabetes Questionnaire of Self-care Activities related to smoking, described in Table 2, it was found that $90 \%(n=45)$ of elderly people reported "no smoking in the last seven days"; of them, 56\% ( $n=28)$ reported, "have never smoked." Of the 05 elderlies (10\%) who reported smoking, all were female and the average number of cigarettes smoked per day was $0.37 \%$ ( \pm 1.02$)$.
Table 2. Results of the elderly related to smoking, according to the Diabetes Questionnaire of Self-care Activities. Campina Grande-PB, Brazil, in 2016

\begin{tabular}{|c|c|c|c|}
\hline Smoking & Frequency & $\mathbf{N}$ & $\%$ \\
\hline \multirow{2}{*}{$\begin{array}{l}\text { Smoking during } \\
\text { the last seven days? }\end{array}$} & No & 45 & 90 \\
\hline & Yes & 5 & 10 \\
\hline \multirow{7}{*}{$\begin{array}{l}\text { When did you } \\
\text { smoke the last } \\
\text { cigarette? }\end{array}$} & Never smoked & 28 & 56 \\
\hline & For over two years & 3 & 6 \\
\hline & One to two years ago & 11 & 22 \\
\hline & $\begin{array}{l}\text { From four to twelve } \\
\text { months ago }\end{array}$ & 3 & 6 \\
\hline & $\begin{array}{l}\text { From one to three } \\
\text { months ago }\end{array}$ & 0 & 0 \\
\hline & Last month & 0 & 0 \\
\hline & Today & 5 & 10 \\
\hline
\end{tabular}

\section{Discussion}

By analyzing the self-care activities for the elderly with DM attended by primary care using the Diabetes Questionnaire of Self-care Activities, there were no statistically significant differences in adherence on gender.

The average adherence obtained in this study showed that regardless of gender, the highest adherence activities were related: "specific food," 
"foot care" and "medical therapy"; and the less adherence "physical activity," "sweet intake" and "monitoring of blood glucose." Of the five items covered on food, "eat fruits and vegetables" showed the highest adherence among the elderly (6.06 \pm 2.16/week). Similar results for these items were also found in other studies that applied Diabetes Questionnaire of Self-Care Activities in elderly populations $[15,17]$.

In diabetes treatment, proper diet is essential since it favors the metabolic control contributing to normalization of blood glucose, reducing cardiovascular risk and weight control, preventing acute and chronic complications of the disease [18]. There is no consensus about the best nutritional screening tool since the literature has limitations, advantages, and disadvantages when used in specific populations. [19]

The low consumption of sweets was another positive aspect found in this study, particularly among elderly men. Another descriptive study of older adults with DM revealed that most of them had the habit of restricting sugar from the diet [20]. According to the Guidelines of the Brazilian Society of Diabetes [21], the use of sugar in a proper diet not exceeding $10 \%$ of the total amount of carbohydrates does not cause glycemic decompensation in diabetic patients.

When asked about the item "performed physical activity for at least 30 minutes" during the last week, an overall average was observed only 1.58 days/week (SD = 2.33), and $62 \%$ of the elderly reported that they had not practiced any day. Similar results were found by other authors who have obtained an average of 1.24 days/week $(S D=2.78)$ for this last item [9].

On the other hand, it is noteworthy that as the average age of this study population is 73.6 years old; this may be one of the factors limiting the practice of regular physical activity among elderly patients, although the existence of social equipment nearby health unit researched that promote physical activity of low impact.
Study of sedentary older women who began to practice regular physical activity observed that this practice when prescribed appropriately, extends the functional independence and improve the quality of life of the elderly, helping to decrease blood sugar levels, Body Mass Index body and the control of blood pressure [22].

Also, the practice of physical activity among the elderly, when associated with a food plan, it may be beneficial to assist in glycemic control in weight loss and increased muscle mass, contributing to the reduction of insulin resistance [21].

In the item on the monitoring of blood glucose, the average was 1.94 days/week $(S D=2,142)$. Moreover, when asked whether this assessment had been carried out according to the number of times recommended by their doctor or nurse of FHU, the average was 1.16 days/week $(S D=2.14)$. Similar results were found in other studies $[9,16]$

It is noteworthy that the elderly respondents in this study reported that the reasons for not assessing the daily blood glucose were related to the lack of medical recommendations for this practice, others mentioned that the professional performs this test during consultations. For the elderly who had glucometer (percentage not evaluated in this study), the reasons for non-daily blood glucose monitoring were related to lack of financial resources to buy the tapes blood glucose.

Blood glucose monitoring is an important intervention in the control and treatment of diabetes. Glycemic control can be monitored by blood glucose fasting, pre-prandial (before meals), post-prandial (after meals) and glycated hemoglobin (HbA1c). The blood glucose levels are used to guide the dose adjustment of drugs used since they indicate the times during the day that is a lack or excess of its action. $\mathrm{HbA1c}$ is the parameter used to assess glycemic control in the medium and long term because it reflects the glucose levels of the last two/three months [1].

The American Diabetes Association [23] recommends that the monitoring of blood glucose is performed three or more times a day for all people 
with diabetes type 1 or type 2 insulin use in multiple doses. In people with good pre-prandial control, but with high HbA1c, monitoring of blood glucose two hours after meals may be helpful. In people with type 2 diabetes using oral hypoglycemic monitoring of blood glucose is not routinely recommended. In elderly people, one glucose monitoring should be established at regular intervals, due to the increased risk of glucose changes due to the presence of multiple comorbidities and geriatric syndromes [24].

However, the decision of what level of glycemic control should be achieved needs to be agreed between the doctor and the patient considering the possible benefits, risks and the availability of the necessary technical resources. The goals also need to consider the age/expectation of the person's life, duration of disease, and associated comorbidities. Greater flexibility of blood glucose monitoring is recommended for people with type 2 diabetes whose onset occurred after 60 to 65 years old [1].

The foot care is one of the self-care aspects of patients with diabetes [16]. On this aspect, there was similar percentage found to be desirable for the seven days of the week, in the evaluation of three items of Diabetes Questionnaire of Self -Care instrument activities related to these activities, corroborating the findings of other studies $[11,25]$. It is recommended that every person with diabetes perform the examination of the feet annually, identifying the risk factors for the development of ulcers and amputation [1.21]. Such actions should be implemented by nurses in routine care to this population, when considering that the diabetic foot is one of the leading causes of hospitalization of people with diabetes [16].

Through frequent foot examination, the prevention carried out by the doctor or nurse in Primary care is vitally important to reduce complications. It is noteworthy that the maintenance of the sensitivity of the feet should be explored for health promotion actions to maintain this condition [7].

In the elderly population, the self-examination of the feet is hampered by visual impairment and de- creased mobility due to aging and the lack of family caregivers. In this regard, the nursing must teach the patient the care they should take, including daily inspection and maintenance of clean and dry feet, especially between the toes, which can prevent costly complications, both physical and emotional. It is noteworthy also the need to encourage the patient to wear closed shoes that fit well, as well as inspect them before putting them [16].

In the assessment of adherence to drug treatment of diabetes, there were means found higher among the female elderly (6.28 days per week $(S D=2.15$ ) for items "took the recommended diabetes pills in the last seven days." These results indicate a good behavior for self-care activities involving drug therapy. Similar results were found by other studies with an average of the last 7 days evaluated $[9,11,16]$.

Medication therapy plays an important role in the treatment of multiple acute and/or chronic health conditions in frail elderly such as diabetes. The low percentages found for the item "took insulin as recommended" is because only $40 \%(n=20)$ of respondents used insulin daily. Among people with diabetes, especially type 2 diabetes, adherence to drug treatment tends to be low due to its asymptomatic nature, leading to the belief that the medication is not required [26].

It is imperative that the person with diabetes is aware of the risk related to the disease and the need for continued use of the drug. In this sense, it is necessary to guide health staff on the correct use of medicines, especially those who have difficulty adhering to treatment [27]. Also, health professionals in general and nursing, in particular, have the mission to promote better adherence to treatment by stimulating the behavioral changes essential to the effective control of the disease Adherence of people with diabetes mellitus self-care with the feet [16].

As for smoking, it is known that consumption is lower among the elderly than for other age groups and even when it occurs, it is related to poor health conditions and lack of control, jeopardizing the 
health and quality of life. In this study, only $10 \%$ (05) of the elderly reported smoking within seven days before the application of Diabetes Questionnaire of Self-Care Activities instrument.

Smoking decreases the longevity, being a risk factor for many diseases, especially respiratory and cardiovascular. The benefits of cigarette suspension are evident and significantly improve the health of ex-smokers [28]. Because they have been exposed for a longer period to cigarettes without filter and high nicotine levels, elderly smokers have a higher risk of being affected by diseases related to smoking than cohorts of later generations. [29]

To improve adherence of the elderly with diabetes to self-care activities, the team of primary health care must continually act as a facilitator, the motivation for the desirable behavioral changes to control the disease, and support the development or strengthening of skills for self-care. Therefore, the educational process for self-care activities must be continuous and updated according to the needs of people identified in each care [13].

\section{Conclusion}

The results demonstrate that the elderly population evaluated has satisfactory adherence to diabetes self-care with a high adherence (average greater than 5 days/week) for self-care activities that involve the intake of five or more servings of fruit/vegetable; examination of the shoes before put them; drying of the toes after washing them; and drug therapy.

Items of the Diabetes Questionnaire of Self-Care Activities that had lower adherence were glucose monitoring and the practice of physical activity. This study revealed that guidance in health education activities related to these items is necessary for this population, considering the specifics of diabetes in the elderly.

It is important to highlight the investments in health should be directed to self-care and treatment of people with diabetes to encourage behavioral changes favoring a reduction of comorbidities and complications related to the disease, especially among the elderly.

It is also believed that the assessment of adherence to self-care activities among older people with diabetes is important to prevent complications that interfere with self-care, quality of life and independence in the active aging process.

It is recommended that researchers and other health professionals use the Diabetes Questionnaire of Self-Care Activities in the care of elderly people in other health care levels, because only with new studies in different scenarios of practice, it can be checked the feasibility of using this instrument in the assessment of self-care among the elderly with diabetes.

\section{List of Abbreviations}

DM: Diabetes Mellitus

FHU: Family Health Unit

MMSE: Mini-Mental State Examination

QAD: Diabetes Questionnaire of Self-Care Activities

SD: Standard Deviation

HbA1: Glycated Hemoglobin

\section{References}

1. Ministério da Saúde (Brasil), Secretaria de Atenção à Saúde. Estratégias para o cuidado da pessoa com doença crônica: diabetes mellitus. Brasília: Ministério da Saúde, 2013.

2. International Diabetes Federation. Idf Diabetes Atlas Seventh Edition. 7 ed. Available from: www.diabetesatlas.org

3. International Diabetes Federation. Atlas do Diabetes 2015 Atualização Available from: http://www.diabetesatlas.org/ resources/2015-atlas.html

4. Stopa SR, César CLG, Segri NJ, Goldbaum M, Guimarães VMV, Alves MCGP, Barros MBA. Self-reported diabetes in older people: comparison of prevalences and control measures. Rev Saúde Pública 2014; 48(4):554-62.

5. Ministério da Saúde (Brasil), Secretaria de Vigilância em Saúde. Vigitel Brasil 2013: vigilância de fatores de risco e proteção para doenças crônicas por inquérito telefônico. Brasília: Ministério da Saúde, 2014. 
6. Sinclair A, Dunning T, Rodriguez-Maña L. Diabetes in older people: new insights and remaining challenges. The Lancet Diabetes \& Endocrinology 2015; 3(4):275-85.

7. Marques MB, Silva MJ, Coutinho JFV, Lopes MVO. Assessment of self-cAre competence of elderly people with diabetes. Rev Esc Enferm USP 2013; 47(2):415-20.

8. Veras VS, Santos MA, Rodrigues FFL, Arrelias CCA, Pedersoli TAM, Zanetti ML. Self-care among patients enrolled in a selfmonitoring blood glucose program. Rev Gaúcha Enferm. 2014; 35(4):42-8.

9. Michels MJ, Coral MHC, Sakae TM, Damas TB, Furlanetto LM. Questionnaire of Diabetes Self-Care Activities: translation, crosscultural adaptation and evaluation of psychometric properties. Arq Bras Endocrinol Metab. 2010; 54(7):644-51.

10. Toobert D, Hampson S, Glasgow R. The summary of diabetes self-care activities measure: results from 7 studies and a revised scale. Diabetes Care. 2000; 23(7):943-50.

11. Gomides DS, Villas-Boas LCG, Coelho ACM, Pace AE. Selfcare of people with diabetes mellitus who have lower limb complications. Acta Paul Enferm. 2013; 26(3):289-93.

12. Veras VS, Santos MA, Rodrigues FFL, Arrelias CCA, Pedersoli TAM, Zanetti ML. Self-care among patients enrolled in a selfmonitoring blood glucose program. Rev Gaúcha Enferm. 2014; 35(4):42-8

13. Coelho ACM, Villas Boas LCG, Gomides DS, Foss-Freitas MC, Pace AE. Self-care activities and their relationship to metabolic. Texto Contexto Enferm. 2015; 24(3):697-705

14. Freitas SS, Silva GRF, Rezende Neta DS, Silva ARV. Analysis of the self-care of diabetics according to by the Summary of Diabetes Self-Care Activities Questionnair (SDSCA). Acta Scientiarum. Health Sciences 2014; 36(1):73-81.

15. Santos GFP, Almas PS, Freitas LM, Kamil JP, Nemer ASA Adhesion to self-care influences the anthropometric and biochemical parameters of type 2 diabetic patients treated in hiperdia program in the Juiz de Fora city, Minas Gerais, Brazil Nutr Clín Diet Hosp. 2014; 34(3):10-9.

16. Rezende Neta DS, Silva ARV, Silva GRF. Adherence to foot self-care in diabetes mellitus patients. Rev Bras Enferm. 2015; 68(1):111-6.

17. Alencar LL, Torres MV, Santos AMB, Santos MB, Santiago AKC, Barbosa APB. Epidemiological profile of elderly patients type 2 diabetes mellitus enrolled in the family health strategy. Rev Eletr Gestão \& Saúde, 2014; 5(5):2972-89.

18. Ferreira EAP, Fernandes AL. Treino em Alta Observação e Adesão a Dieta em Adultos com Diabetes tipo 2. Psic Teor e Pesq. 2009; 25(4):629-36

19. Souza R, Fraga JS, Gottschall CBA, Busnello FM, Rabito El. Anthropometry assessment in the elderly: estimates of weight and height and agreement between BMI ratings. Rev Bras Geriatr Gerontol. 2013; 16(1):81-90

20. Santos I, Guerra RG, Silva LA. Individuals and clinics characteristics of elderly people with diabetes: thematic research in sociopoetic workshop Rev Enferm UERJ. 2013; 21(1):34-40.
21. Sociedade Brasileira de Diabetes (SBD). Diretrizes da Sociedade Brasileira de Diabetes: 2014-2015. Sociedade Brasileira de Diabetes. São Paulo: AC Farmacêutica, 2015.

22. Monteiro LZ, Fiani CRV, Freitas MCF, Zanetti ML, Foss MC. Decrease in Blood Pressure, Body Mass Index and Glycemia after Aerobic Training in Elderly Women with Type 2 Diabetes. Arq Bras Cardiol. 2010; 95(5):563-70.

23. American Diabetes Association. Standards of medical care in diabetes - 2013. Diabetes Care. 2013; 36(1):11-66.

24. Kirkman MS, Briscoe VJ, Clark N, Florez H, Haas LB, Halter JB, Huang ES, Korytkowski MT, Munshi MN, Odegard PS, Pratley RE, Swift CS; Consensus Development Conference on Diabetes and Older Adults. J Am Geriatr Soc. 2012; 60(12):2342-56.

25. Rocha RM, Zanetti ML, Santos MA. Behavior and knowlege: basis for prevention of diabetic foot. Acta Paul Enferm. 2009; 22(1):17-23.

26. Borba AKOT, Marques APO, Leal MCC, Ramos RSPS, Guerra ACCG, Caldas TM. Adherence to drug therapy in diabetic elderly. Rev Rene. 2013; 14(2):394-404.

27. Santos FS, Oliveira KR, Colet CF. Adherence to medical treatment in patients with diabetes mellitus attended at a Public Health Unit in the city of ljuí (RS, Brazil): an exploratory study. Rev Ciênc Farm Básica Apl. 2010; 3(3):223-7.

28. Goulart D, Engroff P, Ely LS, Sgnaolin V, Santos EF, Terra NL, Carli GA. Tabagismo em Idoso. Rev Bras Geriatr Gerontol. 2010; 13(2):313-20

29. Sachs-Ericsson N, Schmidt NB, Zvolensky MJ, Mitchell M, Collins $\mathrm{N}$, Blazer DG. Smoking cessation behavior in older adults by race and gender: the role of health problems and psychological distress. Nicotine Tob Res. 2009; 11(4):433-43.

\section{Publish in International Archives of Medicine}

International Archives of Medicine is an open access journal publishing articles encompassing all aspects of medical science and clinical practice. IAM is considered a megajournal with independent sections on all areas of medicine. IAM is a really international journal with authors and board members from all around the world. The journal is widely indexed and classified Q2 in category Medicine. 